\title{
Isabelle Degauque, Les tragédies de Voltaire au miroir de leurs parodies dramatiques: d'CEdipe (1718) à
} Tancrède (1760)

\section{Franco Piva}

\section{(2) OpenEdition \\ Journals}

\section{Edizione digitale}

URL: http://journals.openedition.org/studifrancesi/8921

DOI: 10.4000/studifrancesi.8921

ISSN: 2421-5856

\section{Editore}

Rosenberg \& Sellier

\section{Edizione cartacea}

Data di pubblicazione: 1 octobre 2008

Paginazione: 458

ISSN: 0039-2944

\section{Notizia bibliografica digitale}

Franco Piva, «Isabelle Degauque, Les tragédies de Voltaire au miroir de leurs parodies dramatiques: d'Édipe (1718) à Tancrède (1760)», Studi Francesi [Online], 155 (LII | II) | 2008, online dal 30 novembre 2015, consultato il 12 janvier 2021. URL: http://journals.openedition.org/studifrancesi/8921; DOI: https://doi.org/10.4000/studifrancesi.8921

Questo documento è stato generato automaticamente il 12 janvier 2021.

\section{cc) (†) $\odot$}

Studi Francesi è distribuita con Licenza Creative Commons Attribuzione - Non commerciale - Non opere derivate 4.0 Internazionale. 


\title{
Isabelle Degauque, Les tragédies de Voltaire au miroir de leurs parodies dramatiques: d'Edipe (1718) à Tancrède (1760)
}

\author{
Franco Piva
}

\section{NOTIZIA}

ISABELLE DEGAUQUE, Les tragédies de Voltaire au miroir de leurs parodies dramatiques: d'Edipe

(1718) à Tancrède (1760), Paris, Honoré Champion («Les Dix-huitièmes Siècles», 104),

2007, pp. 486.

1 Spesso confusa con la satira, la parodia è stata considerata, fino a non molto tempo fa, un genere parassitario, non degno in quanto tale dell'interesse della critica. Da qualche tempo si è tuttavia iniziato a guardare ad essa con maggiore attenzione, in quanto ci si è resi conto che la parodia intrattiene con l'opera presa di mira un rapporto assai più complesso di quanto si fosse potuto supporre, in grado, se bene interpretato, di dire, sull'opera oggetto della parodia, più di quanto non possa, a volte, fare una lettura diretta, in quanto essa pone l'opera in questione in rapporto sia con le attese del pubblico sia con le regole che reggono la sua composizione. Di qui il tentativo di definire meglio la parodia e un'attenzione per questi testi che andasse al di là della semplice curiosità. Presente lungo tutta la storia letteraria francese, la parodia teatrale è parsa fiorire con particolare abbondanza, e probabilmente non per caso, nel Settecento: le quasi mille pièces segnalate, all'inizio del secolo scorso, dalla studiosa americana V. Belt Grannis, ne costituiscono la prova più evidente. Il presente volume si inscrive in questa ondata di interesse.

2 Prendendo come corpus di indagine le parodie delle tragedie composte da Voltaire tra il 1718, anno del suo ingresso nel mondo della tragedia francese con Edipe, ed il 1760, 
anno del suo ultimo grande successo (Tancrède), I. Degauque ha definito un campo di indagine particolarmente interessante in quanto riguarda l'autore tragico più importante di tutto il Settecento francese, e quello che, in piena coscienza, riprende e perpetua i grandi modelli seicenteschi. Se, come sempre succede, le parodie della sue tragedie sono una testimonianza del successo che il suo teatro riscosse presso il pubblico dell'epoca, e se nascono, talvolta, dall'invidia di colleghi meno fortunati, esse dicono in realtà molto di più, come dimostra chiaramente la lucida analisi alla quale le ha sottoposte l'A. del presente volume. Confrontando le tragedie di Voltaire con i canoni dell'estetica classica, questi testi fanno per esempio chiaramente vedere come Voltaire, di fatto, deroghi spesso da quegli stessi canoni di cui si faceva, in piena coscienza e volontà, egli stesso paladino, con derive, verso il romanesque, lo spettacolare, il patetico o l'orribile che indicano non solo i limiti del teatro tragico voltairiano, ma, più in generale, i sintomi della crisi che investì il teatro tragico francese, non solo quello di Voltaire, e gli sforzi che esso compì, anche attraverso Voltaire, per tentare di uscirne. Sicché le parodie offrono spesso delle utilissime chiavi di lettura che consentono, anche al lettore moderno, di entrare meglio dentro a testi che il tempo, o il nome, assai meno noto, del loro autore hanno reso di più difficile accesso.

3 L'analisi di I. Degauque mette però anche in evidenza le diverse strategie e le diverse modalità attraverso le quali la parodia opera sui testi di Voltaire; ciò facendo, essa induce a riflettere sulle forme che la parodia ha assunto storicamente, e non solo nel Settecento, e, di conseguenza, a rivedere le definizioni che di essa hanno dato, non solo i teorici del Settecento, ma anche alcuni storici più recenti, forse a causa dei corpora, quantitativamente e qualitativamente non adeguati, sui quali hanno basato le loro riflessioni e dai quali hanno tratto le loro conclusioni. Alla luce del corpus preso in esame dall'A. del volume, la parodia appare fenomeno assai più complesso ed articolato, che merita, e deve, perciò, essere analizzato con maggiore attenzione, e sulla base di corpora meglio definiti e più significativi, da sottoporre ad analisi più attente e particolareggiate, come è per l'appunto quella condotta da Isabelle Degauque sulle parodie delle tragedie di Voltaire. 